\title{
Medication abortion in missed abortion up to 13 weeks amenorrhoea: a prospective study
}

\author{
Divya R. Prasad*, Neelima V. Nair
}

\begin{abstract}
Department of Obstetrics and Gynecology, Sree Gokulam Medical College and Research Foundation, Venjaramoodu,
\end{abstract} Trivandrum, Kerala, India

Received: 23 August 2016

Revised: 24 August 2016

Accepted: 21 September 2016

\author{
*Correspondence: \\ Dr. Divya R. Prasad, \\ E-mail: ms.divanil@rediffmail.com
}

Copyright: (c) the author(s), publisher and licensee Medip Academy. This is an open-access article distributed under the terms of the Creative Commons Attribution Non-Commercial License, which permits unrestricted non-commercial use, distribution, and reproduction in any medium, provided the original work is properly cited.

\section{ABSTRACT}

Background: Missed abortion is a type of abortion in which the dead fetus is retained within the uterus. The objective of the study was to find out whether the use of medication abortion is safe and effective in termination of missed abortion up to 13 weeks of pregnancy.

Methods: This study was conducted in a tertiary care center as a prospective study, for a period of 24 months from April 2013 to March 2014. Sample size consisted of 150 cases of missed abortion up to 13 weeks of pregnancy which was confirmed by ultrasound. These patients were given medication abortion and was followed up for complications viz., pain, excessive bleeding, need for surgical evacuation, rupture uterus, infection and coagulopathy.

Results: In the present study, $16 \%$ required surgical evacuation. The common complications were pain (8\%), nausea and vomiting $(4.7 \%)$, low grade fever $(3.3 \%)$, excessive bleeding $(6 \%)$. There were no cases of rupture uterus or coagulopathy, or infections.

Conclusions: Medication abortion is a safe and effective method for the termination of missed abortion up to 13 weeks of pregnancy with fewer complications thus reducing the need for surgical methods.

Keywords: Complications, Medication abortion, Missed abortion

\section{INTRODUCTION}

Missed abortion is a type of abortion in which the dead fetus is retained within the uterus. Patients usually present with spotting or vaginal bleeding following a period of amenorrhea. There is regression of the signs and symptoms of pregnancy. Ultrasound is used for diagnosis and it shows an unhealthy irregular sac with irregular margins and absent cardiac activity. ${ }^{1}$ Conventionally, missed abortion is treated by surgical methods like suction evacuation. Medication abortion used for termination of missed abortion includes oral mifepristone and varying doses of vaginal prostaglandin E1 (PGE1) tablets.

$80 \%$ of abortions occur in first trimester. ${ }^{2}$ Use of ultrasound helps to diagnose missed abortion even before the onset of signs and symptoms. If medication abortion proves safe and effective, it will help a large number of patients from undergoing surgical evacuation and its associated complications. This study was conducted with the aim of finding out whether the use of medication abortion is safe and effective in the termination of missed abortion up to 13 weeks of pregnancy.

\section{METHODS}

A prospective study was conducted in a tertiary care center and conducted in the department of Obstetrics and Gynecology for a period of 24 months from April 2013 to Mar 2014. Sample size of 150 cases of missed abortion up to 13 weeks of amenorrhea, confirmed by ultrasound was included in the study. 


\section{Exclusion criteria}

- Women with history of previous caesarian section

- Women with history of previous surgical evacuation

- Women with known hypersensitivity to prostaglandins

I50 patients with ultrasound confirmed missed abortion up to 13 weeks were included in the study. Written informed consent was obtained from these patients. They were given $200 \mathrm{mg}$ of oral Mifepristone. They were admitted 48 hours later in the hospital and were given 800 microgram of vaginal prostaglandin E1 (PGE1) tablets and were observed in the hospital for 4 hours for the onset of bleeding. These patients were discharged after 4 hours. Immediate surgical evacuation was done if there was excessive bleeding following PGE1.These patients were asked to report after 2 weeks for ultrasound confirmation of completeness of abortion. They were asked to report earlier in case of excessive pain, bleeding, fever or abnormal discharge. If the ultrasound done at 2 weeks showed retained products of conception, then surgical evacuation was done. Data collected was analysed using SPSS 20.

\section{RESULTS}

The study population was in the age group 18-40 years. $8 \%$ (12 cases) were 19 years or less, 39\% (59 cases) belonged to 20-24 years, 26\% (39 cases) belonged to 2529 years, $11 \%$ (16 cases) belonged to $30-34$ years and $16 \%$ ( 24 cases) were between 35 and 40 years (Table 1 ).

Table 1: Age group.

\begin{tabular}{|lll|}
\hline Age in years & Number & Percentage \\
\hline$<19$ years & 12 & 8 \\
\hline $20-24$ & 59 & 42 \\
\hline $25-29$ & 39 & 26 \\
\hline $30-34$ & 16 & 11 \\
\hline $35-40$ & 24 & 16 \\
\hline
\end{tabular}

$57 \%$ ( 86 cases) belonged to less than 9 weeks gestational age and $43 \%$ (64 cases) belonged to gestational age between 9 and 13 weeks (Table 2).

Table 2: Gestational age.

\begin{tabular}{|lll|}
\hline Gestational age in weeks & Number & Percentage \\
\hline Less than 9 weeks & 86 & 57 \\
\hline 9-13 weeks & 64 & 43 \\
\hline
\end{tabular}

Completeness of abortion without the need for surgical evacuation was seen in $84 \%$ (126 cases). 6\% (9 cases) underwent evacuation immediately as there was excessive bleeding. Retained products of conception confirmed by USG done at 2 weeks were found in $10 \%$ (15 cases) (Table 3 ).
Table 3: Completeness of abortion.

\begin{tabular}{|llllllll|}
\hline Total & \multicolumn{2}{c}{$\begin{array}{c}\text { Complete } \\
\text { abortion }\end{array}$} & \multicolumn{2}{c|}{$\begin{array}{c}\text { Immediate } \\
\text { evacuation }\end{array}$} & \multicolumn{2}{c|}{ RPOC at 2} \\
weeks \\
\hline No. & $\%$ & No. & $\%$ & No. & $\%$ & No. & $\%$ \\
\hline 150 & 100 & 126 & 84 & 9 & 6 & 15 & 10 \\
\hline
\end{tabular}

Medication abortion was found to be well tolerated.8\% (12 cases) had pain, $3.3 \%$ (5 cases) developed low grade fever with no evidence of infection, $4.7 \%$ (7 cases) developed nausea and vomiting. No major complications like coagulation abnormalities or rupture uterus were seen (Table 4).

Table 4: Complications.

\begin{tabular}{|lll|}
\hline Complications & Number & Percentage \\
\hline $\begin{array}{l}\text { Bleeding requiring } \\
\text { immediate evacuation }\end{array}$ & 9 & 6 \\
\hline RPOC at 2 weeks & 15 & 10 \\
\hline Pain & 12 & 8 \\
\hline Fever & 5 & 3.3 \\
\hline Nausea and vomiting & 7 & 4.7 \\
\hline Rupture uterus & Nil & \\
\hline Infection, coagulopathy & Nil \\
\hline
\end{tabular}

\section{DISCUSSION}

Complete abortion without the need for surgical evacuation was observed in $84 \%$ in our study. No major complications were seen. Bleeding requiring immediate surgical evacuation was seen in $6 \%$ of study population. Retained products of conception at 2 weeks were seen in $10 \%$ of the population on follow up. Study by Wagaarachchi et al showed $84.1 \%$ success rate using same dosage regime. ${ }^{3}$ Study by Nielson et al reported a success rate of $52 \%$ when $400 \mathrm{mg}$ of Mifepristone and 400 microgram of PGE1 was used, both orally. ${ }^{4}$ The slightly lower success rate in this study can be attributed to the fact that PGE1 and Mifepristone was taken orally. Plasma concentrations and bioavailability of PGE1 tend to be higher when administered vaginally rather than orally, Zieman et al. ${ }^{5}$ Vaginal administration of PGE1 has been shown to be more effective in comparison with oral route in context of medication abortion, Crenin et al. ${ }^{6}$ Although incomplete miscarriage may be managed with PGE1 alone, in the presence of early fetal demise, priming with antiprogesterone Mifepristone makes the regime more effective, El Rafaey et al, Hinshaw 1997.,8 WHO task force in 1993 has suggested that for termination of early pregnancy, a single dose of $200 \mathrm{mg}$ of mifepristone is as effective as $600 \mathrm{mg}$, when used in combination with PGE1. ${ }^{9}$ Most studies using PGE1 alone for medical management of delayed miscarriage have a success rate of $13-83 \%$, de Jonge et al. ${ }^{10}$ Overall complete abortion was $97.6 \%$ in a study by PW Ashok et al. ${ }^{11}$ Chung et al, reported an overall efficacy rate of $70.6 \% .^{12}$ Demetrolis et al showed a failure rate of using PGE1 alone to be $23.1 \% .^{13}$ Study by Nguyen et al 
showed a success rate of $94 \% .{ }^{14}$ This is the highest reported success rate reported from a developing country. Side effects of the regime were also assessed. The most common side effects reported were pain, nausea and low grade fever. These are generally in lower range than similar studies. Nguyen et al reported that $6 \%$ had vomiting, 5\% needed immediate evacuation due to excessive bleeding. ${ }^{14}$ Wagaarachchi et al in a similar study reported that $41.6 \%$ required oral analgesia, $<1 \%$ required diclofenac suppository, $17.4 \%$ required opioid analgesics and $1.8 \%$ had pelvic infection. ${ }^{3}$ Our study reported a lower side effect profile. No major complications were reported in our study. Immediate evacuation was needed in $6 \%$ (9 cases) of our population. Side effects were tolerable, though more common than surgical evacuation, and needs only proper counselling.

\section{CONCLUSION}

It is concluded that medication abortion is a safe and effective method of termination of missed abortion up to 13 weeks of amenorrhea; and will prove to be a good alternative to surgical management.

Funding: No funding sources Conflict of interest: None declared

Ethical approval: The study was approved by the ethical committee of GMERS medical college

\section{REFERENCES}

1. Cunningham GF, Norman F. Abortion. Williams Obstetrics $21^{\text {st }}$ Edition. 35:867-868.

2. Harlap S, Shiono PH. Alcohol, smoking, and incidence of spontaneous abortions in the first and second trimester. Lancet. 1980;2:173.

3. Wagaarachchi PT, Ashok PW, Narvekar N, Smith NC, Templeton A. Medical management of early fetal demise using a combination of Mifepristone and Misoprostol. Hum Reprod. 2001;16(9):1849-53.

4. Nielsen S, Hahlin M, PtetZr Christensen JJ. Unsuccessful treatment of missed abortion with a combination of antiprogesterone and a prostaglandin E1 analogue. BJOG. 1997;104:1094-96.

5. Zieman M, Fong S, Benowitz NL. Absorption Kinetics of Misoprostol with Oral or Vaginal Administration. Obstet Gynecol. 1997;90:88-92.

6. Crenin MD, Moyer R, Guido R. Misoprostol for medical evacuation of early pregnancy failure. Obstet Gynecol. 1997;89:768-72.

7. El-Refaey H, Hinshaw K, Henshaw R. Medical management of missed abortion and anembryonic pregnancy. Br Med J. 1992;1399:305.

8. Hinshaw HKS. Medical management of miscarriage. I N Grudzinkas JG, O'Brien PMS. (eds) Problems in early pregnancy: advances in diagnosis and management. RCOG Press, London; 1997:284-295.

9. WHO Task Force. WHO task force on postovulatory methods of fertility regulation. Termination of pregnancy with reduced doses of Mifepristone. Br Med J. 1993;307:532-7.

10. de Jonge ETM, Makin JD, Manefeldt E. Randomized clinical trial of medical evacuation and surgical curettage for incomplete miscarriage. $\mathrm{Br}$ Med $\mathrm{J}$. 1995;311:662.

11. Ashok PW, Penney GC, Flett GMM, Templeton A. An effective regimen for early medical abortion: A report of 2000 consecutive cases. Human Reproduction. 1998;13:2962-5.

12. Chung T, Leung P, Cheung LP. A medical approach to management of spontaneous abortion using misoprostol. Acta Obstet Gynecol Scand. 1997;76:248-51.

13. Demetroulis C, Saridogan E, Kunde D. A prospective randomized control trial comparing medical and surgical treatment for early pregnancy failure. Hum Reprod. 2001;16(2):365-9.

14. Nguyen TNN, Winikoff B, Clark S. Safety, Efficacy and Acceptability of Mifepristone-Misoprostol Medical Abortion in Vietnam International Family Planning Perspectives. 1999;25(1):10-14.

Cite this article as: Prasad DR, Nair NV.

Medication abortion in missed abortion up to 13 weeks amenorrhoea: a prospective study. Int $\mathbf{J}$ Reprod Contracept Obstet Gynecol 2016;5:3840-2. 